\title{
Mental and physical health in general population during COVID-19: Systematic review and narrative synthesis
}

Authors' Contribution: A Study Design B Data Collection C Statistical Analysis D Data Interpretation E Manuscript Preparation F Literature Search G Funds Collection

\author{
Feifei Wang ${ }^{A B D E F}$, Szilvia Boros ${ }^{\text {DEF }}$ \\ Institute of Health Promotion and Sport Sciences, Faculty of Education and Psychology \\ ELTE Eötvös Loránd University, Budapest, Hungary
}

\section{abstract}

Background: The outbreak of COVID-19 changed the normality of daily life. Due to mobility restriction measures, physical and mental health in general population became a remarkable concern for researchers and health professionals.

Material and methods:

This article briefly reviews the evidence of mental and physical health consequences during COVID-19 pandemic. The review was conducted in October 2020 through PubMed and Web of Science with the searching frame: Mental health and Physical health and COVID-19. The study selection process followed the PRISMA flow diagram.

Results: The reported mental consequences were mainly negative psychological effects including stress symptoms, anxiety, and depression. The total physical activity in MET- minutes/week demonstrated a statistically significant reduction between before and during COVID-19 pandemic. Specifically, males showed higher significant variation of $\Delta$-MET compared with females $(p<0.001)$. Also, the reduction of total physical activity was related to worse psychological well-being $(r=0.07541, p<0.001)$.

Conclusions: In the general population, both mental and physical health consequences call for academic concern, and investigation from different social layers of population needs to be justified. Discovery of mental and physical promotion interventions to outline the psychological, social, and physiological aspects of the pandemic are required.

Key words: COVID-19; mental health; physical activity; lockdown; quarantine.

\section{article details}

Article statistics:

Full-text PDF:

Copyright Indexation:

Funding:

Conflict of interests:

Corresponding author:

Open Access License:

Word count: 2,675; Tables: 2; Figures: 2; References: 26

Received: November 2020; Accepted: January 2021; Published: March 2021

http://www.balticsportscience.com

(c) Gdansk University of Physical Education and Sport, Poland

Celdes, Clarivate Analytics Emerging Sources Citation Index (ESCI), CNKI Scholar (China National Knowledge Infrastructure), CNPIEC, DOAJ, EBSCO - Central \& Eastern European Academic Source, EBSCO - SPORTDiscus, EBSCO Discovery Service, Google Scholar, Index Copernicus, J-Gate, Naviga (Softweco, Primo Central (ExLibris), ProQuest - Family Health, ProQuest - Health \& Medical Complete, ProQuest - Illustrata: Health Sciences, ProQuest Nursing \& Allied Health Source, Summon (Serials Solutions/ProQuest, TDOne (TDNet), Ulrich's Periodicals Directory/ ulrichsweb, WorldCat (OCLC)

This research received no specific grant from any funding agency in the public, commercial, or not-for-profit sectors. Authors have declared that no competing interest exists.

Feifei Wang MSc, PhD student, Kazinczy utca 23-27, Budapest 1075, HUNGARY; e-mail: feifei.wang@ppk.elte.hu; phone: +36 70 2833412; ORCiD: 0000-0001-7781-8722

This is an open access article distributed under the terms of the Creative Commons Attribution-Non-Commercial-NoDerivatives 4.0 International (https://creativecommons.org/licenses/by-nc-nd/4.0/), which permits use, distribution and reproduction in any medium, provided the original work is properly cited, the use is non-commercial and is otherwise in compliance with the license. 


\section{INTRODUCTION}

On January 23, 2020, the Chinese government announced lockdown to respond to the coronavirus virus outbreak in Wuhan [1]. On 30 January 2020, the World Health Organization (WHO) declared the coronavirus virus SARS-CoV-2 as an international public health emergency. In a short time, SARS-CoV-2 swept across the world, inducing a global epidemic of COVID-19 disease. The pandemic has resulted in worldwide public health concern and become a global health threat [2]. With the increasing cumulative cases worldwide, more and more countries executed the lockdown policy since February 2020. Mobility restriction measurements such as curfew, home-based quarantine, confinement, etc. were adopted as prevention strategies to control the spreading and infection rate of the virus. In addition, a number of countries implemented social distancing, travel bans, cancellation of sporting and other mass participation events, and changes to work practices, which have dramatically affected daily life.

Researchers have deployed multiple resources to understand the psychological, social, and neuroscientific effects of the COVID-19 pandemic. It is already evident that the direct and indirect psychological and social effects of the COVID-19 pandemic are pervasive and could affect mental health [3-4]. Given that the changes in the ways that people normally engage in everyday activities impact health and well-being, the health concern is prevalent for those in self-isolation or quarantine, where feelings of depression, fear, guilt, and anger may occur [5]. Also, a neuropsychiatric linkage between the outbreak of acute emergency and mental distress impacts the general population, which has led to long-term social unrest [6]. It has been reported that depression symptoms indicate a considerable psychological morbidity in response to acute natural disasters in the general population [7]. During the COVID-19 pandemic, healthy residents are recommended to keep physical distance and wear masks, which may exacerbate the negative effects; thus, the mental and physical health consequences among the general population should be of great concern.

An increasing number of studies have highlighted potential health consequences during COVID-19. Previous research found that mental health is associated with physical activity, sleep quality, and quality of life in both clinical and nonclinical populations [8]. In addition, the severity of the COVID-19 outbreak has an indirect effect on negative emotions by affecting sleep quality [9]. COVID-19 pandemic has restricted physical activity, which may lead to reduced endurance capacity, loss of muscle strength and mass, tendon ruptures and reduced joint tribology [10]. Therefore, the mental health and physical health should be emphasized especially during and after the COVID-19 epidemic.

The mental and physical health consequences after COVID-19 have rarely been discussed. Based on the present knowledge, this study reviewed the existing evidence about mental and physical health during COVID-19 period in order to provide a better understanding of the public health concern in the general population.

In view of the above, this study aims (1) to highlight the importance of mental health and physical health during COVID-19; (2) to review mental and physical health among general population during COVID-19; (3) and to provide better understanding of the mental and physical health consequences during COVID-19.

\section{MATERIAL AND METHODS}

\section{Database searCh}

The search strategy followed the Preferred Reporting Items for Systematic Reviews and Meta-Analyses (PRISMA) [11]. Keywords were extracted from a preliminary review of the 
literature, the search was performed in two databases: PubMed and Web of Science. The search structure was: Mental health AND Physical health AND COVID-19. The quality of the included studies was assessed by using the Study Quality Assessment Tools (NIH). The present review involved cross-sectional studies and systematic review studies; therefore, two tools were adopted: Quality Assessment of Systematic Reviews and Meta-Analyses; Quality Assessment Tool for Observational Cohort and Cross-Sectional Studies. Figure 1 shows the results of the quality assessment of the included articles. The search was completed in October, 2020.

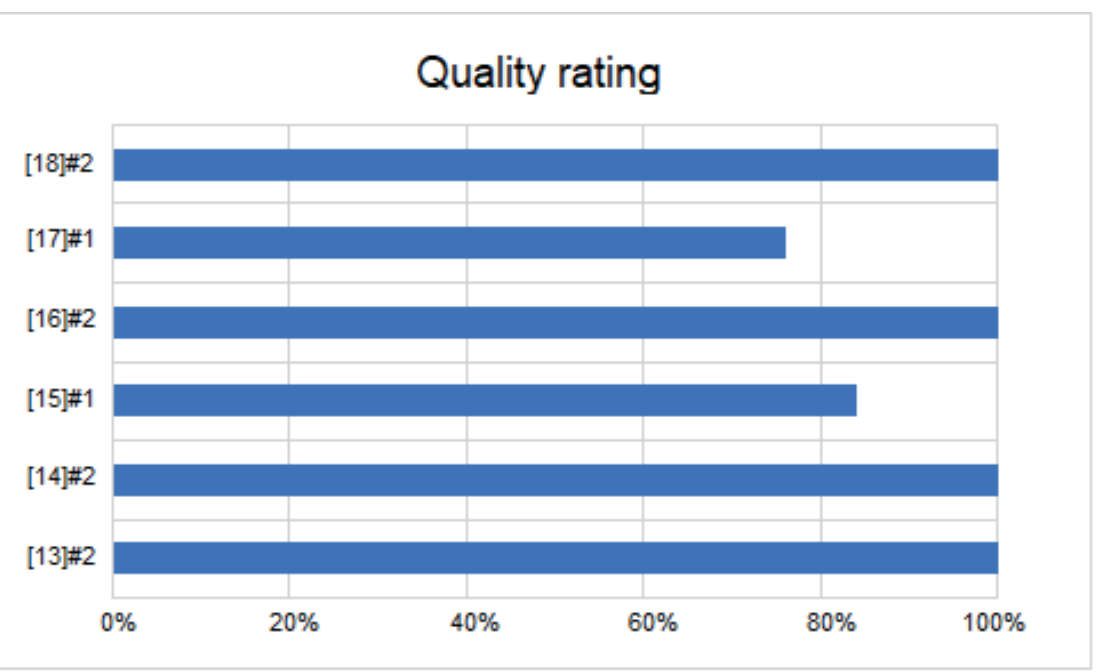

Fig. 1. The quality assessment of the included articles

\#1: Quality Assessment of Systematic Reviews and Meta-Analyses

\#2: Quality Assessment Tool for Observational Cohort and Cross-Sectional Studies

\section{INCLUSION AND EXCLUSION CRITERIA}

The review sought to identify papers that described or reviewed a general population from mental and physical health perspective during the COVID-19 pandemic. The research highlighting mental health studies increased rapidly due to the confinement policy, and this review concerned with the current state of mental and physical health especially among the general population. The time frame of the data search included studies that were published or were in press between January 2020 and December 2020. The inclusion criteria were as follows: studies were conducted in the context of COVID-19 epidemic, studies focused on general citizens, studies were published in English, studies were available in full-text. The exclusion criteria applied to studies that involved in healthcare professional including nurses, doctors, and clinical physicians, studies were short reports or mini interpretive reviews of mental and physical health concern.

\section{BIAS ASSESSMENT}

The included studies were limited to those of a cross-sectional nature and systematic reviews. Given that there is no software to assess the publication bias, we used the Cochrane Collaboration Risk of Bias tool [12] to assess all of the included articles. The Cochrane tool examined all of the included studies from 5 domains: adequacy of allocation sequence; allocation concealment; blinding of participants, personnel, and outcome assessors; incomplete outcome data; selective outcome reporting. The detailed risk of bias assessment is listed in Table 1. 
Table 1 Assessment of risk of bias

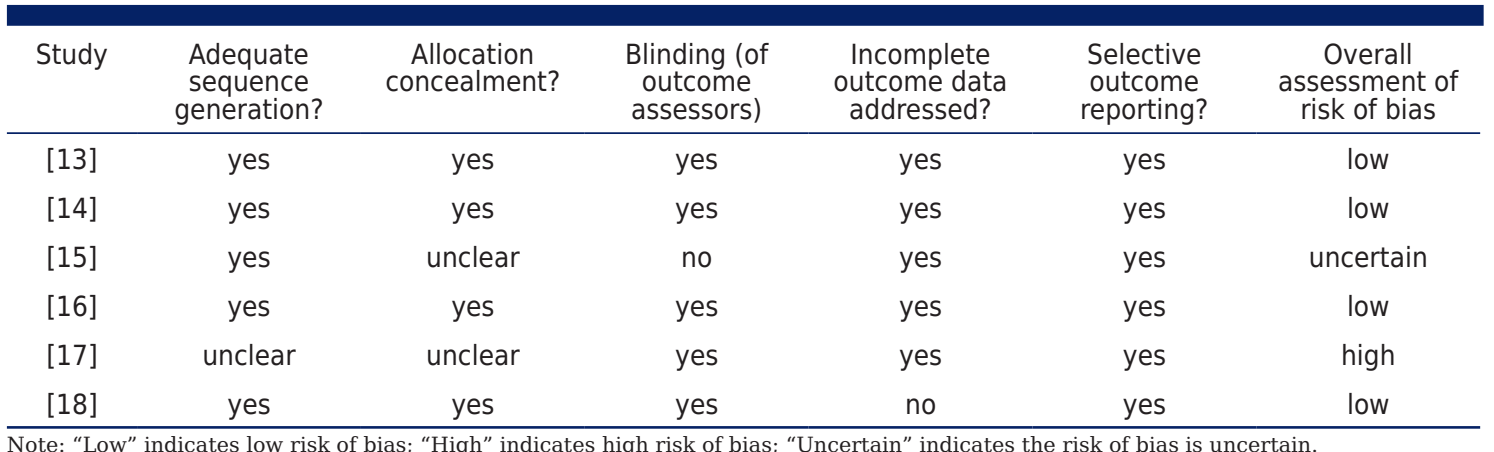

\section{Data ANaLYsis}

The variety of study purposes, subjects, and reported outcomes meant that a meta-analysis was unfeasible, so a narrative summary of the included studies was prepared to draw conclusions. One significance of the present review was to have comprehensive evidence supporting the mental and physical health consequences among general population during and after a period of COVID-19.

\section{RESULTS}

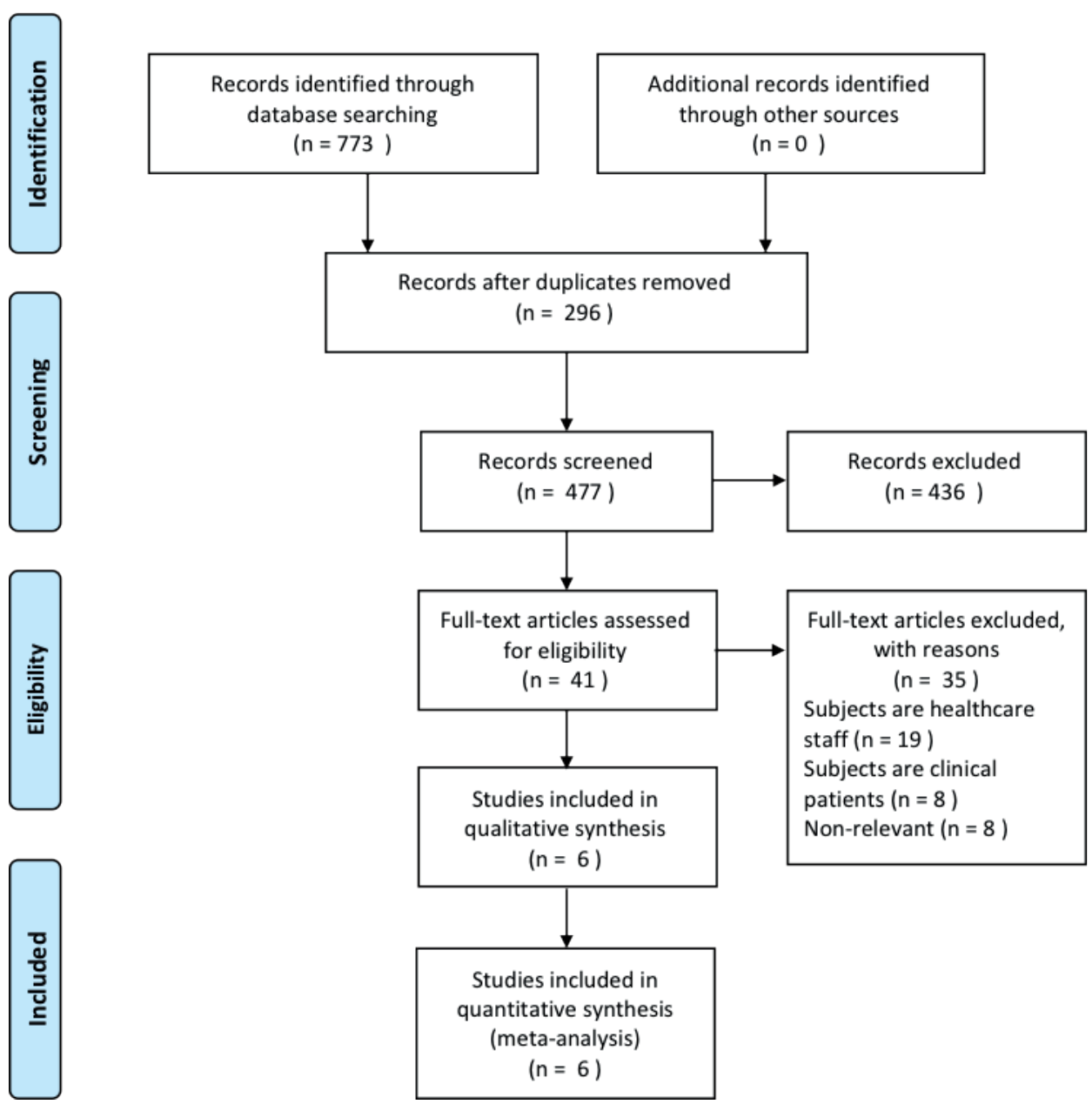

Fig. 2 Preferred Reporting Items for Systematic Reviews and Meta-Analyses flow diagram 
In total, 773 articles were retrieved using the search term in the two databases. Of these, 41 were selected for the full-text review, and 6 were selected for inclusion in the narrative review. The selection flow diagram and the reasons for exclusion in the full-text review stage are presented in detail in Figure 2. The included articles focus on the interaction between mental health and physical health during the COVID-19 pandemic, among which two articles emphasized the implications of mental health. The number of studies discussing physical health was scant compared with the number of studies highlighting mental health.

\section{STUDY CHARACTERISTICS}

The characteristics of the included studies are summarized in Table 2. The included articles $(n=6)$ cover subjects from Australia $(n=1)$, China $(n=1)$ and Italy $(n=2)$. Through literature search, we detected similar articles focusing on mental health conducted in different regions, we only selected the study conducted at the country level and involving a representative sample size. Two articles were systematic review articles, and the remaining four articles were cross-sectional studies. The two systematic studies were included because they provided useful information for the present review, for instance, the crosssectional studies provided prevalence data of mental and physical health among the general population; one systematic review [15] also reviewed the prevalence data in a much broader context. The other review study provided additional data on mental health consequences of quarantine and physical distance. All articles were selected purposefully based on the objectives of the present review study.

Table 2 The characteristics of the included articles

\begin{tabular}{|c|c|c|c|c|c|}
\hline Study & Participants & Country & Study design & Main variables & Measurements/Scales \\
\hline [13] & $\begin{array}{l}1491 \text { adults } \\
\text { (mean age } 50.5 \\
\pm 14.9 \text { years, } \\
67 \% \text { female). }\end{array}$ & Australia & $\begin{array}{l}\text { cross-sectional } \\
\text { study }\end{array}$ & $\begin{array}{l}\text { depression, } \\
\text { anxiety, stress; } \\
\text { physical activity; } \\
\text { sleep and alcohol } \\
\text { use }\end{array}$ & $\begin{array}{l}\text { Depression, Anxiety and } \\
\text { Stress Scale (DASS 21); } \\
\text { Active Australia Survey } \\
\text { (AAS); Alcohol Use } \\
\text { Disorder Identification Test } \\
\text { Consumption (AUDIT-C) }\end{array}$ \\
\hline$[14]$ & $\begin{array}{l}1738 \\
\text { respondents } \\
\text { from } 190 \\
\text { Chinese cities }\end{array}$ & China & $\begin{array}{l}\text { cross-sectional } \\
\text { study }\end{array}$ & $\begin{array}{l}\text { post-traumatic } \\
\text { stress disorder } \\
\text { (PTSD); stress, } \\
\text { anxiety and } \\
\text { depression }\end{array}$ & $\begin{array}{l}\text { Impact of Event Scale- } \\
\text { Revised (IES-R); Depression, } \\
\text { Anxiety and Stress Scale } \\
\text { (DASS-21); }\end{array}$ \\
\hline [16] & $\begin{array}{l}2524 \text { subjects } \\
\text { (56.4\%female) }\end{array}$ & Italy & $\begin{array}{l}\text { cross-sectional } \\
\text { study }\end{array}$ & $\begin{array}{l}\text { physical } \\
\text { activity energy } \\
\text { expenditure; } \\
\text { mental well- } \\
\text { being }\end{array}$ & $\begin{array}{l}\text { International Physical } \\
\text { Activity Questionnaire; } \\
\text { Psychological General Well } \\
\text { Being Index }\end{array}$ \\
\hline [17] & $\mathrm{N} / \mathrm{A}$ & $\mathrm{N} / \mathrm{A}$ & review study & $\begin{array}{l}\text { nutrition; } \\
\text { physical activity }\end{array}$ & $\mathrm{N} / \mathrm{A}$ \\
\hline$[18]$ & $\begin{array}{l}18147 \\
\text { respondents } \\
\text { (79.6\% women) }\end{array}$ & Italy & $\begin{array}{l}\text { cross-sectional } \\
\text { study }\end{array}$ & $\begin{array}{l}\text { post-traumatic } \\
\text { stress } \\
\text { symptoms; } \\
\text { depression, } \\
\text { anxiety, } \\
\text { insomnia, } \\
\text { perceived stress, } \\
\text { and adjustment } \\
\text { disorder } \\
\text { symptoms }\end{array}$ & $\begin{array}{l}\text { Post-traumatic stress } \\
\text { symptoms (PTSS); Patient } \\
\text { Health Questionnaire (PHQ- } \\
\text { 9); Generalized Anxiety } \\
\text { Disorder scale (GAD-7); } \\
\text { Insomnia Severity Index } \\
\text { (ISI); Perceived Stress } \\
\text { Scale (PSS); International } \\
\text { Adjustment Disorder } \\
\text { Questionnaire (IADQ) }\end{array}$ \\
\hline
\end{tabular}




\section{Prevalence of mental and physical health during COVID-19}

In this study, the prevalence of mental health and physical health among the general population during the COVID-19 pandemic was assessed. One systematic review study that involved databases including Science Direct, Scopus, Embase, PubMed, Google Scholar and Web of Science databases focusing on stress, depression and anxiety during COVID-19 reported that prevalence of stress with a total sample size of 9,074 is $29.6 \%$ (95\% confidence limit: $24.3-35.4$ ), the prevalence of anxiety with a sample size of 63,439 is $31.9 \%$ (95\% confidence interval: 27.5-36.7), and the prevalence of depression with a sample size of 44,531 people is 33.7\% (95\% confidence interval: 27.5-40.6) [15]. Furthermore, during the pandemic, the levels of anxiety, depression and stress were significantly higher in younger individuals (18-45 years) compared to older subjects [13].

Governments prohibited a great majority of outdoor exercise and social activities (e.g. going to the gym) and imposed social distancing and containment of movement measures, which may result in a reduction of physical activity. The search results showed that the total physical activity in MET- minutes/week demonstrated a statistically significant difference between before and during COVID-19 pandemic (mean: 2429 vs. 1577 MET-min/ wk, $\mathrm{p}<0.001$ ) [16]. During COVID-19 confinement, percentage of low active individuals increased up to $39.62 \%$ [16]. Moreover, males showed higher significant variation of $\Delta$-MET compared with females $(\mathrm{p}<0.001)$. Even though the World Health Organization (WHO) released "Stay physically active during self-quarantine" guidance on how to stay active and reduce sedentary behavior while at home, little was known about the effects of home-based physical activity [17].

\section{Mental AND PHySiCAL health CONSEQUenCes AFter COVID-19}

Research evaluated the mental health and assessed the physical activity level during COVID-19, whereas, limited attention was paid to the period of the pandemic. The existing data in the present review indicated that mental health symptoms such as anxiety, depression and stress were commonly accompanied with modified lifestyles including physical exercise behavior. Given the differences in socio-cultural characteristics and historical context, which obviously impact people's behavior and attitudes, the mental and physical health consequences may differ after the period of COVID-19. In a population study in China, no significant difference was found regarding stress $(t=-0 \cdot 30, p>0.05$, 95\% CI: $0.79-0.58)$, depression $(t=-0 \cdot 41, p>0.05,95 \%$ CI: $0.77-0.50)$ and anxiety $(t=$ $0 \cdot 36, p>0.05,95 \%$ CI: $0.58-0.60$ ) at the beginning and during the pandemic [15]. In Italy, researchers found high rates of negative mental health outcomes (17.3\% for depression, $20.8 \%$ for anxiety, $21.8 \%$ for high perceived stress in the general population [18].

Research showed that the reduction of total physical activity was related to worse psychological well-being ( $r=0.07541, p<0.001)$ [17]. Specifically, the association was significant in the group of young adults rather than in other age groups $(r=0.1168$, $\mathrm{p}<0.001)$. The association was significant in high active $(\mathrm{r}=0.1322, \mathrm{p}<0.001)$ and moderate active $(r=0.1322, \mathrm{p}<0.001)$ participants rather than low active participants $(\mathrm{r}=0.08157, \mathrm{p}=0.05)$ [17]. Nevertheless, reduced physical activity was positively associated with an increase in smoking, alcohol intake, depression, anxiety and stress [13]. The results from literature suggested that a reduction of physical activity is associated with deleterious health outcomes including mental and physical health. Limited physical activity and inability to take a regular walk out of one's home as a consequence of collective quarantine, which may be associated with several metabolic effects that would increase the cardiovascular risk [17]. 


\section{DISCUSSION}

This study reviewed the prevalence of mental health effects and changes in physical activity and presented comparative data on mental and physical health in the general population following the COVID-19 pandemic. Mental and physical health consequences through cross-sectional and literature review studies have been interpreted by examining 6 related articles. Moreover, this study analyzed evidence from different regions. The mental and physical health may be negatively influenced by COVID-19, but the detailed changes tailoring to social characteristics, culture etc. should be highlighted.

A number of reports suggest COVID-19 contributes to severe psychological impacts [19-20]. Researchers have largely highlighted the negative impacts of COVID-19 on psychological distress [18]. However, through the data reviewed in the present study, depression, anxiety and stress scores are in relation to different sociodemographic and health characteristics. Females are more vulnerable than males when a stressful situation occurs, such as the rapid pandemic of COVID-19, but there are no significant differences regarding depression and anxiety [13]. The mean scores for depression, anxiety and stress are mostly within the normal to mild range when compared with the scores before pandemic [15], which indicates that even though the sudden pandemic caused increased panic, the overall mental health disorder is still at a low level [18]. The prevalence of light to moderate depression, anxiety and stress level is much more significant than the moderate to severe level. It is possible that the distress level may be a result of media post and government policy [21]. In addition, mental health indicators regarding gender, age, education, and region should also be taken into consideration [22-23].

The decrease in physical activity has been reported during COVID-19, and it is suggested that people should maintain home-based exercise to keep healthy [24]. Without doubt, the non-essential business closure policy from government reduced the accessibility to gyms or physical activity clubs. In the general population, it is highly believed that the COVID-19 pandemic could increase physical inactivity. In fact, the total physical activity has considerably decreased [25]. However, despite the total physical activity, sedentary, moderate or moderate-to-vigorous activity need to be analyzed separately in order to provide specific results. As reported in a national survey conducted in Brazil, one-third of the participants spent more than $10 \mathrm{~h}$ per day sitting, but still, nearly half of the participants spent more than 30 min per day on moderate to vigorous physical activity (MVPA) [26]. Therefore, research focus needs to specify which group of people are under worse physical inactivity rather than simply describe the whole population when discussing physical inactivity during the COVID-19 pandemic.

Several limitations of this study need to be mentioned. Given the policies and socio-cultural chiropractic are different across regions, mental and physical reaction to COVID-19 may differ in different populations. The COVID-19 is still spreading and there is no evidence suggesting how the trend will go, people's responses may change overtime. Therefore, the results from different time points of COVID-19 pandemic should be justified accordingly.

\section{CONCLUSIONS}

The mental and physical health implications among the general population have drawn dominant concern from public health experts and researchers during the COVID-19 pandemic. Literature has largely described the positive effect exerted by physical activity to ameliorate psychological and general health. Thus, detailed and practical recommendations for mental and physical health are needed. According to the results in this study, it can be concluded that the COVID-19 pandemic can affect mental and physical health at the population level, but it still calls for a clarified understanding. Therefore, in the cur- 
rent epidemic, it is important to identify individual community groups and compare the regional differences, so that with appropriate interventions and attentions, the mental and physical health among general population is improved.

\section{REFERENCES}

[1] Bai Y, Yao L, Wei T, et al. Presumed asymptomatic carrier transmission of COVID-19. JAMA. 2020;323:1406-1407. https://doi.org/10.1001/jama.2020.2565

[2] Wang C, Horby PW, Hayden FG, Gao GF. A novel coronavirus outbreak of global health concern. The Lancet. 2020;395:470473. https://doi.org/10.1016/S0140-6736(20)30185-9

[3] Holmes EA, O'Connor RC, Perry VH, et al., Multidisciplinary research priorities for the COVID-19 pandemic: A call for action for mental health science. Lancet Psychiatry. 2020; April 15. https://doi.org/10.1016/S2215-0366(20)30168-1

[4] Szabo A, Ábel K, Boros S. Attitudes toward COVID-19 and stress levels in Hungary: Effects of age, perceived health status, and gender. Psychol Trauma. 2020;12:572-575. https://doi.org/10.1037/tra0000665

[5] Brooks SK, Webster RK, Smith LE, Woodland L, Wessely S, Greenberg N, et al. The psychological impact of quarantine and how to reduce it: rapid review of the evidence. The Lancet. 2020; February 26. https://doi.org/10.1016/S01406736(20)30460-8

[6] Neria Y, Nandi A, Galea S. Post-traumatic stress disorder following disasters: a systematic review. Psychol Med. 2008;38:467. https://doi.org/10.1017/S0033291707001353

[7] Galea S, Ahern J, Resnick H, et al. Psychological sequelae of the September 11 terrorist attacks in New York City. N Engl J Med. 2002;346:982-987. https://doi.org/10.1056/NEJMsa013404

[8] Feng Q, Du Y, Ye YL, He QQ. Associations of physical activity, screen time with depression, anxiety and sleep quality among Chinese college freshmen. PLoS One. 2014;9(6):e100914. https://doi.org/10.1371/journal.pone.0100914

[9] Zhang Y, Zhang H, Ma X, Di Q. Mental Health Problems during the COVID-19 Pandemics and the Mitigation Effects of Exercise: A Longitudinal Study of College Students in China. Int J Environ Res Public Health. 2020;17:3722. https://doi.org/10.3390/ijerph17103722

[10] Paoli A, Musumeci G. Elite aathletes and COVID-19 lockdown: Future health concerns for an entire sector. 2020; 5(2):30. https://doi.org/10.3390/jfmk5020030

[11] Moher D, Liberati A, Tetzlaff J, Altman DG. The PRISMA Group. Preferred Reporting Items for Systematic Reviews and Meta-Analyses: The PRISMA Statement. PLoS Med. 2009;6:e1000097. https://doi.org/10.1371/journal.pmed.1000097

[12] Higgins JP, Altman DG, Gøtzsche PC, et al. The Cochrane Collaboration's tool for assessing risk of bias in randomised trials. BMJ. 2011;343:d5928. https://doi.org/10.1136/bmj.d5928

[13] Stanton R, To QG, Khalesi S, Williams SL, et al. Depression, anxiety and stress during COVID-19: Associations with changes in physical activity, sleep, tobacco and alcohol use in Australian adults. Int J Environ Res Public Health. 2020;17(11):4065. https://doi.org/10.3390/ijerph17114065

[14] Wang C, Pan R, Wan X, Tan Y, Xu L, McIntyre RS, et al. A longitudinal study on the mental health of general population during the COVID-19 epidemic in China. Brain, behavior, and immunity. 2020;87:40-48. https://doi.org/10.1016/j. bbi.2020.04.028

[15] Salari N, Hosseinian-Far A, Jalali R, et al. Prevalence of stress, anxiety, depression among the general population during the COVID-19 pandemic: A systematic review and meta-analysis. Glob Health. 2020;16:1-11. https://doi. org/10.1186/s12992-020-00589-w

[16] Maugeri G, Castrogiovanni P, Battaglia G, et al. The impact of physical activity on psychological health during Covid-19 pandemic in Italy. Heliyon. 2020;6:e04315. https://doi.org/10.1016/j.heliyon.2020.e04315

[17] Mattioli AV, Sciomer S, Cocchi C, Maffei S, Gallina S. Quarantine during COVID-19 outbreak: changes in diet and physical activity increase the risk of cardiovascular disease. Nutr Metab Cardiovasc Dis. 2020;30:1409-1417. https:// doi.org/10.1016/j.numecd.2020.05.020

[18] Rossi R, Socci V, Talevi D, et al. COVID-19 pandemic and lockdown measures impact on mental health among the general population in Italy. Front Psychol. 2020; August 7. https://doi.org/10.3389/fpsyt.2020.00790

[19] Rodríguez-Rey R, Garrido-Hernansaiz H, Collado S. Psychological impact and associated factors during the initial stage of the coronavirus (COVID-19) pandemic among the general population in Spain. Front Psychol. 2020; June 23. https://doi.org/10.3389/fpsyg.2020.01540

[20] Serafini G, Parmigiani B, Amerio A, Aguglia A, Sher L, Amore M. The psychological impact of COVID-19 on the mental health in the general population. QJM. 2020;113:531-537. https://doi.org/10.1093/qjmed/hcaa201

[21] Torales J, O'Higgins M, Castaldelli-Maia JM, Ventriglio A. The outbreak of COVID-19 coronavirus and its impact on global mental health. Int J Soc Psychiatry. 2020; MArch 31. https://doi.org/10.1177/0020764020915212

[22] Jiménez-Pavón D, Carbonell-Baeza A, Lavie CJ. Physical exercise as therapy to fight against the mental and physical consequences of COVID-19 quarantine: Special focus in older people. Prog Cardiovasc Dis. 2020;63:386-388. https:// doi.org/10.1016/j.pcad.2020.03.009

[23] Pieh C, Budimir S, Probst T. The effect of age, gender, income, work, and physical activity on mental health during coronavirus disease (COVID-19) lockdown in Austria. J Psychosom Res. 2020;136:110186. https://doi.org/10.1016/j. jpsychores.2020.110186

[24] Hammami A, Harrabi B, Mohr M, Krustrup P. Physical activity and coronavirus disease 2019 (COVID-19): Specific recommendations for home-based physical training. Manag Sport Leis. 2020;1-6. https://doi.org/10.1080/2375047 2.2020 .1757494

[25] Ricci F, Izzicupo P, Moscucci F, et al. Recommendations for physical inactivity and sedentary behavior during the coronavirus disease (COVID-19) pandemic. Front Public Health. 2020; May 12. https://doi.org/10.3389/ fpubh.2020.00199 
Baltic Journal of Health and Physical Activity 2021; 13 (1): 91-99

82Journal of Gdansk University of Physical Education and Sport

e-ISSN 2080-9999

[26] Schuch FB, Bulzing RA, Meyer J, et al. Associations of moderate to vigorous physical activity and sedentary behavior with depressive and anxiety symptoms in self-isolating people during the COVID-19 pandemic: A cross-sectional survey in Brazil. Psychiatry Res. 2020;292:113339. . https://doi.org/10.1016/j.psychres.2020.113339

Cite this article as:

Wang F, Boros S

Mental and physical health in general population during COVID-19: Systematic review and narrative synthesis

Balt J Health Phys Act. 2021;13(1):91-99

doi: 10.29359/BJHPA.13.1.10 